\title{
Ensino e avaliação: um estudo a partir da realidade dos desafios da aprendizagem
}

Neste artigo refletiremos sobre o atual sistema de avaliação da aprendizagem em nossas escolas, possibilita aos professores se sentirem com autoridade, prestígio e poder para emitir um juízo sobre os alunos que determinará a sua aprovação, reprovação e até mesmo evasão da escola, sem levar em consideração outros elementos do processo de ensino e do contexto social que interferem nesse veredicto. Dessa forma, a avaliação, que deveria ser vista como mais um elemento a serviço da aprendizagem e do crescimento dos alunos, figura como um refúgio para salvaguardar o prestígio e a autoridade do professor e para impor a ordem e a obediência, $\mathrm{O}$ aluno, na maioria das vezes, passa a emitir as respostas que 'o professor deseja', privando-se assim de criar, de duvidar, de refletir. Agindo dessa forma, os alunos asseguram a sua aprovação, que para eles geralmente interessa mais do que participar ativamente de um processo de construção do conhecimento. O momento da avaliação, que poderia ser uma parada para refletir sobre o processo e uma coleta de informações para refazer o percurso ou prosseguir o trabalho, limita-se à mera quantificação do desempenho do aluno, prendendo-se às formalidades de final de bimestre. No processo de ensino, a avaliação não deve ser um aspecto dissociado deste, trabalhado isoladamente, mas sim, parte integrante do processo educativo, que contribua para a sua análise e reflexão, possibilitando assim uma assimilação efetiva por parte do aluno, dos conhecimentos transmitidos.

Palavras-chave: Avaliação; Ensino; Aprendizagem; Desafios; Escola.

\section{Teaching and evaluation: a study from reality learning challenges}

In this article we will reflect on the current learning assessment system in our schools, enabling teachers to feel authoritative, prestigious and empowered to make a judgment about students that will determine their passing, failing and even dropping out of school, without taking into consideration other elements of the teaching process and the social context that interfere with this verdict. Thus, evaluation, which should be seen as another element in the service of student learning and growth, is a refuge to safeguard the teacher's prestige and authority and to impose order and obedience. most of the time, he starts to give the answers that the teacher wants, thus refraining from creating, doubting, reflecting. Acting in this way, students ensure their approval, which for them generally matters more than actively participating in a knowledge-building process. The timing of the assessment, which could be a pause to reflect on the process and a collection of information to retrace or continue the work, is limited to merely quantifying student performance by sticking to the end-of-quarter formalities. In the teaching process, the assessment should not be a dissociated aspect of this, worked in isolation, but rather an integral part of the educational process, which contributes to its analysis and reflection, thus enabling the student to effectively assimilate the knowledge. transmitted.

Keywords: Evaluation; Teaching; Learning; Challenges; School.

Topic: Pedagogia (Educação Criança e Adolescente)

Reviewed anonymously in the process of blind peer.
Received: 22/03/2019

Approved: 15/07/2019
Maurício Bueno da Rosa

Universidade Federal de Santa Catarina, Brasil

http://lattes.cnpq.br/9881608222559155

http://orcid.org/0000-0003-1407-357X

mauriciobueno7@hotmail.com

\section{Referencing this:}

ROSA, M. B.. Ensino e avaliação: um estudo a partir da realidade dos desafios da aprendizagem. Educationis, v.7, n.2, p.14-18, 2019. DOI: http://doi.org/10.6008/CBPC2318-3047.2019.002.0002 


\section{INTRODUÇÃO}

A avaliação da aprendizagem escolar tem sido basicamente utilizada visando medir a quantidade de informação que o aluno reteve, dentro do conteúdo trabalhado pelo professor em sala de aula, através da mensuração e quantificação dos acertos e erros apresentados e da mera classificação dos alunos por meio de notas e ou conceitos, terminando aí o processo de avaliação, que é concebido como um único momento isolado das demais situações do processo educativo. Sendo assim, ao findar a avaliação, os resultados desta, além de não auxiliarem os alunos na constatação e superação de suas dificuldades, não são usados da mesma forma como base para a reestruturação do trabalho do professor.

Conclui-se, a partir do que afirma Caldeira (2000) que a avaliação tem um fim em si mesma, servindo apenas para classificar os alunos e para o, professor identificar aqueles que aprenderam e aqueles que não aprenderam, e mesmo sabendo disto, ele não utiliza esse dado como ponto de partida na revisão do seu trabalho. Na visão de Fernandes (2009)

Os procedimentos de avaliação, na maioria das vezes se dão revestidos de um caráter essencialmente disciplinar, usados que são como forma de assegurar a participação e frequência dos alunos às aulas e como garantia do poder e autoridade do professor, não como momento de reflexão sobre o seu papel de educador.

\section{DISCUSSÃO TEÓRICA}

Em decorrência disso, o fracasso é sempre atribuído ao aluno e as justificativas desse fracasso são dadas pelo professor das mais diversas formas: os alunos não estudam, não têm assistência em casa, não têm 'base', não se interessam pelos estudos, têm deficiências de aprendizagem, etc.. Há de se ter consciência que a avaliação não mede somente aspectos que dizem respeito ao aluno, mas principalmente, oferece valiosas informações sobre o desempenho do professor, sobre a efetividade dos métodos e materiais didáticos utilizados e ainda sobre as condições em que se deu ou não a aprendizagem. Por isso mesmo, a avaliação não é algo estático, faz parte de uma dinâmica mais ampla, que não ocorre em um determinado momento da prática educativa, mas que deve figurar diariamente no trabalho do educador. Para Caldeira (2000)

Avaliar pressupõe definir princípios, em função de objetivos que se pretendam alcançar, estabelecer instrumentos para a ação e escolher caminhos para atingir o fim, verificar constantemente a caminhada, de forma crítica, levando em consideração todos os elementos envolvidos no processo.

O professor precisa então ter claro para si: para que ensinar o que ensinar e como ensinar e ainda a quem ele irá ensinar, procurando em sua prática, fazer a ligação dialética desses elementos, garantindo ao aluno a assimilação dos conteúdos transmitidos e o conhecimento do que se espera dele ao final do processo. O papel da avaliação é de ir delineando nesse percurso, como o aluno se encontra frente ao que se estabeleceu como metas a alcançar.

Para Hoffmann (1996), a avaliação subsidia decisões a respeito da aprendizagem dos educandos, tendo em vista garantir a qualidade do resultado que estamos construindo. Por isso não pode ser estudada, definida e delineada sem um projeto que a articule. Esse projeto, a meu ver, assume características mais 
amplas, pois abarca não só o trabalho do professor em sala de aula, que inegavelmente se liga a uma visão de mundo, de sociedade, do papel da escola e do compromisso com os educandos.

O papel da avaliação é de extrema importância no processo de ensino, levando em conta os altos índices de reprovação e evasão encontrados nas escolas brasileiras de ensino fundamental, visto que reprovação e evasão passam necessariamente pela verificação dos resultados que compõem procedimentos de avaliação. Dessa forma, para Hoffmann (1996)

A escola, dentro de uma proposta liberal, é vista como um lugar de livre acesso, a todos aqueles que nela quiserem ingressar, ignorando-se as diferenças de condições das crianças provenientes das classes baixas, que veem na escola uma possibilidade de se 'integrarem' aos grupos dominantes.

É principalmente através da avaliação inadequadamente utilizada que os professores exercem o seu poder de reprovar ou eliminar da escola, aqueles alunos que não foram capazes de alcançar uma nota suficiente para aprovação. Ela é portanto, uma ação eminentemente social, produto de determinado tipo de sociedade, podendo se constituir em uma arma poderosa contra as crianças que lutam para permanecer na escola pública, ao atender as prerrogativas que Ihe são atribuídas em uma sociedade classista.

Segundo Caldeira (2000) quando se coloca a avaliação, como um dos elementos que têm papel preponderante no processo de ensino, que articulada aos demais componentes desse mesmo processo, pode contribuir decisivamente para a efetivação de uma prática educativa coerente e crítica, é necessário destacar então quais os objetivos que a avaliação da aprendizagem escolar passaria a ter.

Os objetivos da avaliação, nessa perspectiva, seriam principalmente assegurar aos alunos a assimilação ativa dos conhecimentos, buscando formas para que essa assimilação se dê, através de uma reflexão sobre a ação, ou seja, a avaliação, nas suas várias nuances se prestaria fundamentalmente para rever o processo, subsidiando decisões a respeito da condição do aluno e do trabalho do professor no decorrer do mesmo.

No entanto, o que se observa na prática educativa das escolas, é uma avaliação voltada para as questões de aprovação e reprovação do aluno, com objetivo meramente classificatório, visando um resultado final, expresso em nota ou conceito, para atender a legislação vigente. O foco de atenção do aluno para com o estudo, é desviado para a nota, símbolo da autoridade do professor e do 'poder' que exerce ao julgá-lo. O aluno recebe através dela seu atestado de competência ou incompetência, e o processo de avaliar para, exatamente onde deveria começar. Esse processo classificatório, pode significar a eliminação dos alunos oriundos das classes baixas.

As modalidades tradicionalmente levantadas com relação à avaliação são aquelas definidas por Bloom como a avaliação diagnóstica, avaliação formativa e avaliação somativa. Para Hoffmann (1996), o que se pode argumentar com relação a essas modalidades de avaliação é que elas foram tomadas como etapas estanques dentro do processo de ensino, visto a sua utilização ter sido padronizada para o início (diagnostica) no decorrer (formativa) e para o final do processo educativo (somativa), o que acaba por desvincular a avaliação da globalidade do processo.

Uma visão com relação às funções que a avaliação da aprendizagem pode assumir na escola é aquela 
que, segundo Vasconcellos, chegou até nós através dos trabalhos de Bourdieu e Passeron que afirmam que se pode compreender completamente porque tantos traços da avaliação e de seu funcionamento como processo patente de seleção obedecem ainda à lógica que rege a eliminação que esse dissimula. Assim, uma análise das funções do exame que pretende romper com a sociologia espontânea leva a substituir o estudo puramente quantitativo do exame, que serve ainda às funções ocultas do exame, por um estudo sistemático dos mecanismos de eliminação, como ponto privilegiado da apreensão das relações entre o funcionamento do sistema de ensino e a perpetuação da estrutura da relação de classes.

Para Vasconcellos (2005) "os mecanismos de avaliação assumem então na escola, a função de reproduzir as relações sociais vigentes no capitalismo, objetivando a sua perpetuação". Argumentam ainda que o exame (avaliação) serve para exprimir, inculcar, sancionar e consagrar valores solidários com a cultura, através de mediações como a organização do sistema escolar e a estrutura do campo intelectual.

Fernandes (2009) afirma que podemos "entender a avaliação como "estudo sistemático dos mecanismos de eliminação/manutenção", mecanismos estes determinados pela origem social do aluno. Entende ainda que é pela prática da avaliação que a atual organização do trabalho pedagógico se impõem de forma autoritária, expressando relações de poder que estão presentes nos elementos constitutivos do planejamento (objetivos-conteúdos-métodos). Desvendar as relações e implicações que estão por trás das práticas avaliativas é compreender a ideologia em que essas práticas se apoiam, na busca de sua superação. Vasconcellos (2005) afirma que

As funções da avaliação são potencialmente duas: o diagnóstico e a classificação. Da primeira se supõe que permita ao professor e ao aluno detectar os pontos fracos desta e extrair as consequências pertinentes sobre onde colocar posteriormente a ênfase no ensino e na aprendizagem. A segunda, tem por efeito hierarquizar os alunos, estimular a competição, distribuir desigualmente as oportunidades escolares e sociais e assim sucessivamente. A escola prega em parte a avaliação com base na primeira função mas a emprega fundamentalmente para a segunda.

A função diagnostica da avaliação pode ser de grande valia para o professor na sala de aula, na medida em que este seja capaz de retirar dela elementos para conduzir a sua prática, repensar a sua ação e refazer o seu percurso, se necessário. Para Silva et al. (2010)

A atual prática da avaliação escolar estipulou como função do ato de avaliar a classificação e não o diagnóstico, como deveria ser constitutivamente. Ou seja, o julgamento de valor que ter ia a função de possibilitar uma nova tomada de decisão sobre o objeto avaliado, passa a ter a função estática de classificar um objeto ou um ser humano histórico, num padrão definitivamente determinado. Do ponto de vista da aprendizagem escolar poderá ser definitivamente classificado como inferior, médio ou superior.

A classificação dos alunos em níveis, por si só, opera como mecanismo paralisador da dinamicidade do trabalho pedagógico, visto que ao atribuir um valor determinado a cada aluno, encerra-se aí o seu processo de avaliação, ao passo que para se tornar uma ação significativa que contribuísse para a assimilação do conhecimento repassado, a avaliação haveria de se fazer presente em todo o processo. informando ao professor como o aluno está caminhando, reorientando-o na tomada de decisões necessárias à continuidade do trabalho. 


\section{CONCLUSÕES}

Alguns chamam a atenção para a função de controle, que pode estar presente na função diagnostica da avaliação. Hoffmann (1996) nos diz que como a função de controle é indesculpável para a grande maioria das instituições escolares, e se tornou um valor dominante mesmo naquelas que, como o ensino fundamental, não têm uma função explicitamente seletiva, a mentalidade do corpo docente é condicionada por essa função. Obscurecendo minhas relações mais pedagógicas e de poder na classe. Qualquer modificação ou proposta feita nas abordagens de avaliação causada por qualquer motivo, como desejar um melhor conhecimento dos alunos com avaliações mais abrangentes, ter uma avaliação contínua etc., será recuperada, de alguma forma, inevitavelmente, para a faceta controladora da avaliação do aluno. Esse efeito de recuperação apresentado pela faceta controladora da avaliação deve ser levado em consideração ao se propor propostas de ação para professores dentro do sistema educacional.

No entanto, acredito que a despeito deste risco e a despeito de poder se denominar de controle o acompanhamento contínuo, este contribuirá para com o professor na execução do seu trabalho. Nos parece claro que a concepção que o professor tem de avaliação e do seu papel no processo de ensino é que vai determinar a sua postura com relação às funções que ela exerce. Investir na formação de professores e na reciclagem daqueles que já atuam nas escolas se coloca então como ponto básico para conseguir ultrapassar o 'senso-comum' a respeito da avaliação.

\section{REFERÊNCIAS}

CALDEIRA, A. M. S.. Avaliação e processo de ensino aprendizagem. Belo Horizonte: Presença Pedagógica, 2000.

FERNANDES, D.. Avaliar para aprender: fundamentos, práticas e políticas. São Paulo: Unesp, 2009.

HOFFMANN, J.. Avaliação mito e desafio: uma perspectiva construtivista. 20 ed. Porto Alegre: Mediação, 1996.
SILVA, J. F.; HOFFMANN, J.; ESTEBAN, M. T.. Práticas avaliativas e aprendizagens significativas em diferentes áreas do currículo. 8 ed. Porto Alegre: Mediação, 2010.

VASCONCELLOS, C. S.. Avaliação da aprendizagem: práticas de mudanças - por uma práxis transformadora. 7 ed. São Paulo: Libertad, 2005.

A CBPC - Companhia Brasileira de Produção Científica (CNPJ: 11.221.422/0001-03) detém os direitos materiais desta publicação. Os direitos referem-se à publicação do trabalho em qualquer parte do mundo, incluindo os direitos às renovações, expansões e disseminações da contribuição, bem como outros direitos subsidiários. Todos os trabalhos publicados eletronicamente poderão posteriormente ser publicados em coletâneas impressas sob coordenação da Sustenere Publishing, da Companhia Brasileira de Produção Científica e seus parceiros autorizados. Os (as) autores (as) preservam os direitos autorais, mas não têm permissão para a publicação da contribuição em outro meio, impresso ou digital, em português ou em tradução. 